\title{
Um Estudo de Caso de um Sistema Especialista Implementado com JBoss Drools
}

\author{
Fábio de Jesus Lima Gomes ${ }^{1}$, Francisco Marcos da Silva Rocha ${ }^{1}$ \\ 1Departamento de Informação, Ambiente, Saúde e Produção Alimentícia (DIASPA) \\ Instituto Federal do Piauí (IFPI) - Campus Teresina Central - Teresina, PI - Brasil \\ fabiodifpi.edu.br, fmarcosrochadgmail.com
}

\begin{abstract}
RESUMO: O presente trabalho mostra a implementação de um sistema especialista com o uso do JBoss Drools no Sistema de Gerenciamento e Controle de Benefício Estudantil do Instituto Federal do Piauí (IFPI). Esta implementação objetiva mapear de forma centralizada, organizada e gerenciável as regras e restrições observadas na POLAE (Política de Assistência Estudantil). O sistema implementado intercepta a requisição de cadastro de benefício e retorna ao usuário o diagnóstico que seria dado por um assistente social, aprovando ou negando (neste caso, citando também o motivo) a referida requisição.
\end{abstract}

\section{Introdução}

No sentido de reduzir as desigualdades educacionais entres os estudantes, em especial aos oriundos de famílias em situação de vulnerabilidade social, e propiciar a formação integral a partir de programas diversificados que os assistam na sua complexidade frente às distintas necessidades, foi instituída, no ano de 2014, a POLAE (Política de Assistência Estudantil) Instituto Federal do Piauí (IFPI) contemplando no âmbito desta instituição vários tipos de benefícios estudantis, tais como, alimentação estudantil, assistência à saúde e monitoria. Na POLAE estão normatizadas as regras e restrições para cada tipo de benefício ao qual um estudante queira concorrer.

Existia no Instituto Federal do Piauí (IFPI) um sistema para o registro das assistências estudantis, o SIASE (Sistema de Gerenciamento e Controle de Assistência Estudantil), porém o trabalho de verificar se o estudante teria direito ao benefício ofertado era analisado manualmente por um assistente social. Assim, houve a necessidade de se implementar no SIASE algum mecanismo que organizasse e restringisse as regras e restrições observadas na POLAE. Além disso, havia a necessidade de se implantar uma integração com as informações necessárias nativas de outros sistemas no processo de análise da requisição, como por exemplo, alguns dados dos alunos que poderiam ser pesquisados no sistema acadêmico existente, tais como, índice acadêmico parcial, índice de freqüência e situação atual da matrícula.

Este trabalho apresenta a solução para o problema supracitado, onde foi implementado um módulo de um sistema especialista que organiza regras e restrições de forma confiável e simplificada de forma a reduzir ao máximo sua dependência com a lógica do SIASE - haja vista a possibilidade de futuras mudanças na POLAE - e que tenha papel fundamental para auxiliar o assistente social no processo de seleção. De forma simplificada, o módulo recebe uma requisição, verifica as regras para o tipo de benefício requisitado e os atributos necessários do estudante requisitante, tendo como resultado final a aprovação da requisição ou a negação (e seu motivo).

A organização do conteúdo abordado neste artigo foi feita da seguinte forma: a seção 2 apresenta conceitos sobre sistema especialista. A seção 3 detalha o funcionamento do JBoss Drools. A seção 4 apresenta o modulo implementado para solução do problema e a seção 5 apresenta a conclusão e trabalhos futuros.

\section{Sistema Especialista}


Sistemas Especialistas constituem uma classe de sistemas da Inteligência Artificial que executam funções semelhantes àquelas normalmente executadas por um especialista humano, permitindo representar o conhecimento ou perícia humana necessários. [Sellmer 2013].

A estrutura básica de um sistema especialista é formada por: base de conhecimento, motor de inferência e interface com o usuário (Figura 1). A base de conhecimento pode ser composta por um conjunto de regras, fatos e heurísticas que correspondem ao conhecimento do especialista do domínio do sistema. O motor de inferência é responsável por direcionar a busca pelas regras que estão armazenadas na base de conhecimento a serem avaliadas. A interface com o usuário deve ser amigável e flexível garantindo a interação entre sistema especialista e usuário, durante o processamento. [Mendes 1997].

$\mathrm{Na}$ implementação do sistema especialista em questão, utilizou-se o JBoss Drools.

\section{JBoss Drools}

O JBoss Drools é um sistema de gerenciamento de regras de negócio que provê uma interface Web para gerenciamento das regras e uma biblioteca Java para desenvolvimento. É um projeto open

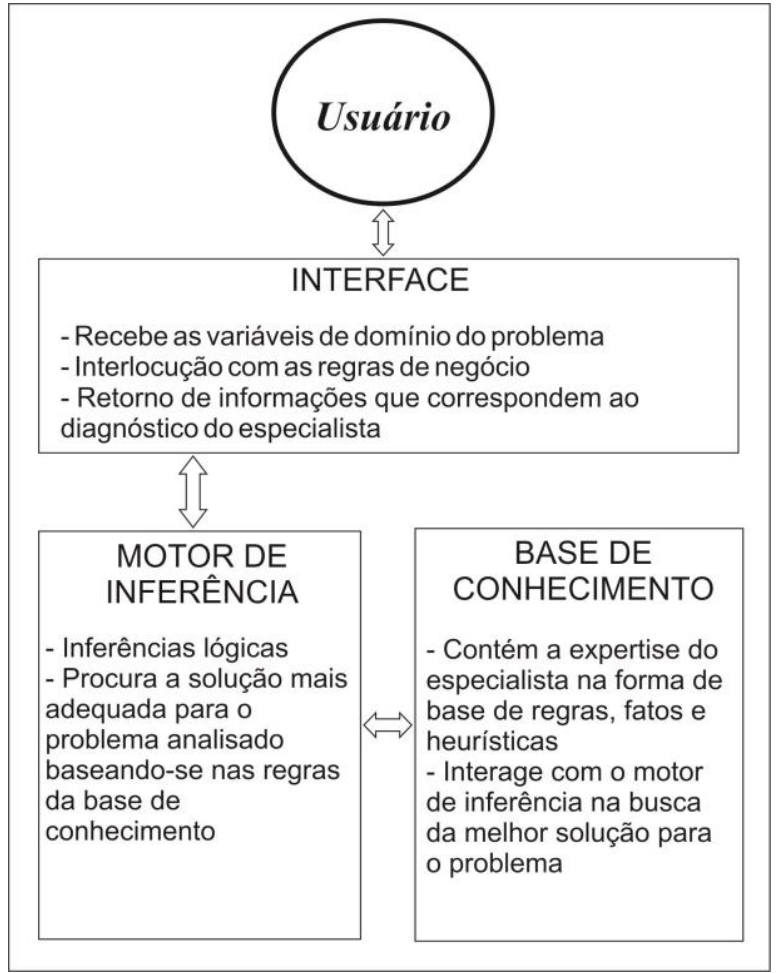

Figura 1. Estrutura básica de um Sistema Especialista [Mendes 1997] source cuja principal função é mapear eventos de negócio e as regras que irão ser satisfeitas para que os eventos aconteçam. [Browne 2009].

\subsection{Regras}

Basicamente, o fluxo de entrada e de saída divide-se em LHS (Left Hand Side) - lado esquerdo da regra -, que especifica o conjunto de condições e RHS (Right Hand Side) - lado direito da regra -, que especifica as ações que serão realizadas com a satisfação do seu LHS (Figura 2). Cada regra também possui, opcionalmente, atributos responsáveis por fornecer uma maneira declarativa para influenciar o seu comportamento, por exemplo: definir a sua prioridade perante outras regras durante o processo de inferência.

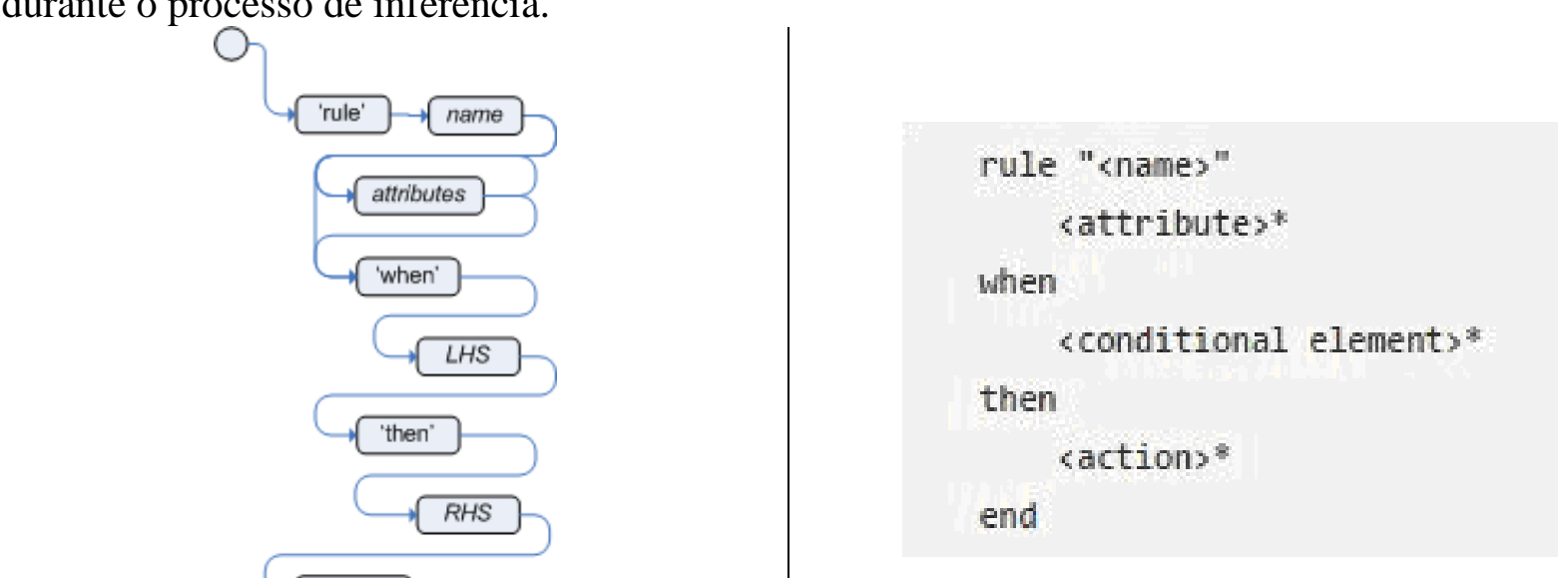

Figura 2. Fluxo básico nas regras do Drools. [Drools 2015]

Figura 3. Visão geral da sintaxe de uma regra no arquivo "drl" do Drools. [Drools 2015] 
A base de conhecimento é implementada em arquivo texto no formato "drl" (Figura 3) contendo as regras, consultas e funções, bem como algumas definições como importação, atributos globais e atributos locais. A linguagem nativa para mapeamento das regras é a DSL (Domain Specific Languages) que é um tipo de linguagem dedicado a um domínio específico [Fowler 2010]. Através dessa linguagem têm-se uma visualização mais amigável da estrutura da regra por um usuário qualquer do sistema.

A seguir, apresentaremos o módulo implementado com o auxílio do JBoss Drools.

\section{Módulo SIASE Rules}

O módulo de sistema especialista implementado no SIASE, denominado SIASE Rules, foi desenvolvido em Java e se utiliza da biblioteca drools-core para o processo de análise de requisição e ligação com o arquivo DRL do sistema o qual podem ficar externos ao pacote de código. Dessa forma o SIASE funciona como interface, o SIASE Rules funciona como interceptador e motor de inferência transparente ao usuário na requisição de novo cadastro de benefício estudantil e o arquivo DRL como base de conhecimento mapeada em regras baseadas na POLAE.

As regras de negócio implementadas no SIASE Rules são correspondentes às possíveis situações de retorno quando da requisição de um benefício (vide exemplo na Tabela 1).

Tabela 1. Esboço da regra: Cumulatividade não permitida [do autor 2017]

\begin{tabular}{|c|c|c|c|}
\hline Nome da regra & Atributo(s) & Condições (quando) & Ações (faça) \\
\hline \multirow[t]{4}{*}{$\begin{array}{l}\text { Cumulatividade } \\
\text { não permitida }\end{array}$} & \multirow[t]{4}{*}{$\begin{array}{l}\text { Prioridade } \\
\text { média }\end{array}$} & $\begin{array}{l}\text { Estudante regularmente } \\
\text { matriculado no período corrente }\end{array}$ & \multirow[t]{2}{*}{ Negar requisição } \\
\hline & & \multirow{2}{*}{$\begin{array}{l}\text { Estudante já possui um benefício } \\
\text { não cumulativo ativo }\end{array}$} & \\
\hline & & & \multirow{2}{*}{$\begin{array}{l}\text { Definir motivo: estudante já } \\
\text { possui benefício não } \\
\text { cumulativo }\end{array}$} \\
\hline & & $\begin{array}{l}\text { O benefício de requisição é do } \\
\text { tipo não cumulativo }\end{array}$ & \\
\hline
\end{tabular}

\subsection{Funcionamento}

Para a inicialização do fluxo de dados numa requisição é necessário que seja informado através da interface pelo menos a matrícula do estudante e o tipo de benefício a ser solicitado; e se necessário outros dois atributos: lista de benefícios ativos do estudante e um mapa de mensagens contendo atributos que não são registrados em nenhum sistema, como por exemplo um boolean de situação socioeconômica favorável. A figura 4 (na página seguinte) mostra o fluxograma de atividades.

Os dados considerados de maior importância no processo de requisição ficam armazenados na memória de produção e na memória de trabalho, representados pelo arquivo DRL e pelos objetos e atributos instanciados na preparação, respectivamente. Após a junção das duas memórias o trabalho de análise de requisição fica por conta do Drools Expert: módulo interno do Drools responsável pelas escolhas e execução das regras. [Schneiders 2011].

Além das regras com critérios para aprovação e negação de um determinado benefício, há também regras com restrições universais para qualquer que seja o benefício solicitado e regras para correção de erros na requisição, tais como, a restrição total a estudantes do PRONATEC ou EAD.

\section{Conclusões e Trabalhos Futuros}

O modelo de centralização da base de conhecimento se torna cada vez mais possível a partir de programas que gerenciem exclusivamente as regras de negócio. Com a aplicação do JBoss Drools no SIASE as regras e restrições que regem a POLAE se tornaram mais claras e flexíveis, uma vez desacopladas da codificação abrem maiores possibilidades de futuras alterações no sistema. Além 
de uma maior organização das regras de negócio, é importante ressaltar a escalabilidade na adição de novas regras que venham a surgir.

Para trabalhos futuros, sugere-se:

a) Realizar um estudo de desempenho relativo ao tempo de resposta durante a requisição;

b) Implementar uma outra interface Web para que o próprio estudante possa simular a solicitação de algum benefício, o possibilitando saber o prévio resultado;

c) Aplicar técnicas de Machine Learning para descobrir padrões nos benefícios cadastrados e nos perfis dos beneficiários, afim de antecipadamente auxiliar o assistente social.

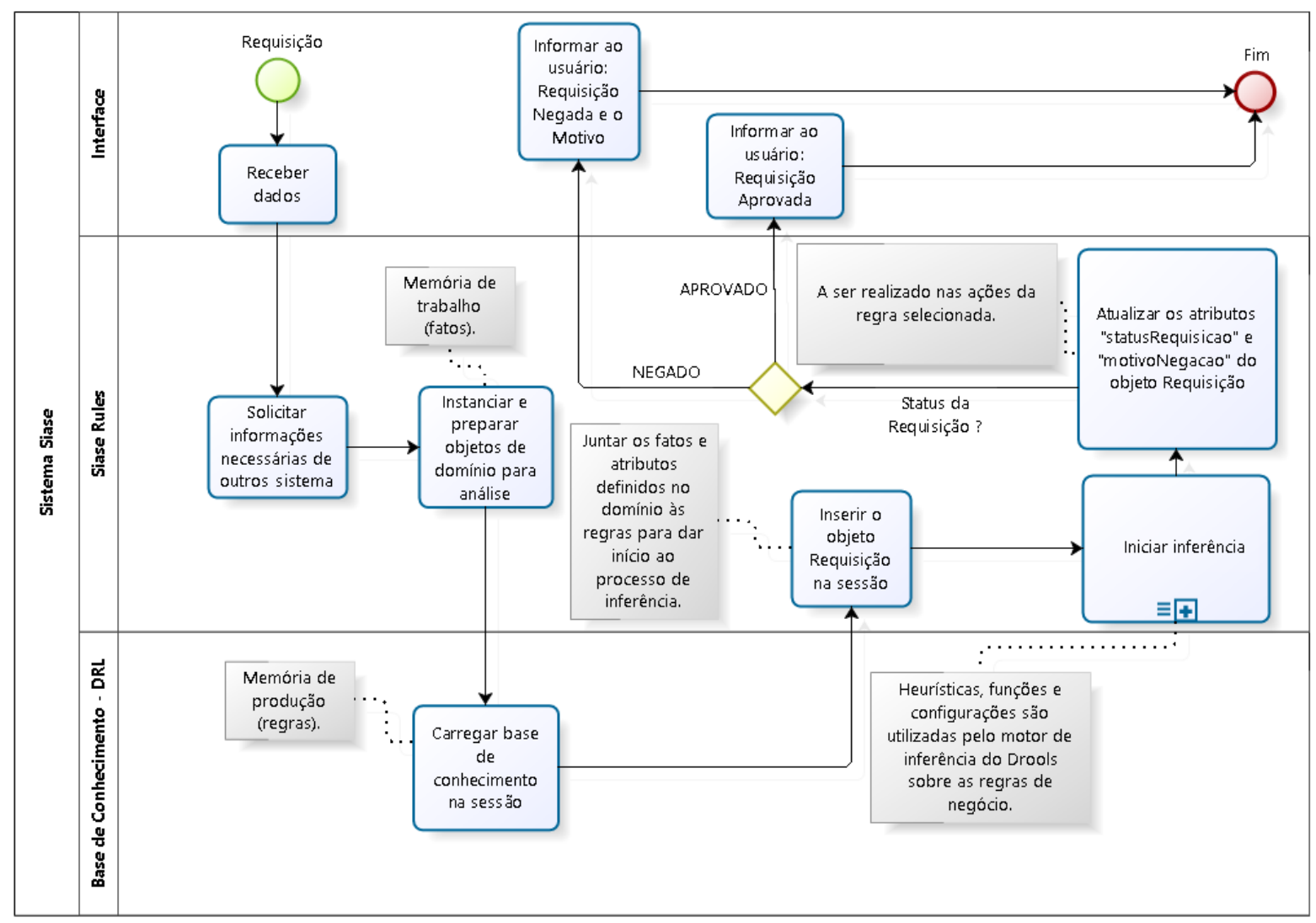

Figura 4. Fluxograma de atividades do sistema [do autor 2017]

\section{Referências}

Browne, P. (2009). JBoss Drools Business Rules. 1.ed. Birmingham: Packt Publishing Ltd. 304 p.

Drools Documentation. v 6.1.0. Final. (2015). Disponível em:

<http://docs.jboss.org/drools/release/6.1.0.Final/drools-docs/html_single/>. Acesso em $01 \mathrm{de}$ Setembro de 2016.

Fowler, M. (2010). Domain-Specif Languages. 1. ed. Boston: Addison-Wesley. 640 p.

Mendes, R. D. (1997). Inteligência artificial: sistemas especialistas no gerenciamento de informação. Ci. Inf., Brasília, DF, n. 1, p. 39-45, jan/abr.

Schneiders, M. A. (2011). Adoção de JBoss Drools no desenvolvimento de sistemas. Blumenau: FURB. 50p.

Sellmer, D. et al. (2013). Sistema especialista para apoiar a decisão na terapia tópica de úlceras venosas. Rev. Gaúcha Enferm. Porto Alegre, RS, p. 154-162. 